\section{Pediatric Radiology}

Lawrence A. Davis, M.D. Pp.185, illustrated. Baltimore: The Williams and Wilkins Co. London: Baillière, Tindall \& Cox. 196r. $72 s$.

'Pediatric Radiology' by Lawrence A. Davis is Chapter XIV from the three volume loose-leaf edition of Golden's Diagnostic Radiology issued as a separate monograph on Pædiatric Radiology.

It describes what it styles pediatric radiological technique which is followed by a succession of chapters on the various systems of the body. The text briefly describes the clinical entity which the plates purport to illustrate. The monograph is a text book on radiology and must be judged by the quality of the plates. Fig. $49 \mathrm{~A}$ has not been correctly centered. The child is lying obliquely across the film. Fig. 52 illustrates a safety pin near the head. Fig. 70 shows more pins. Fig. 76 is again crooked and Fig. 77 shows more pins. Fig. 79 illustrates ' a two-day old male'. The following is the legend. 'The marker is on the anal dimple. The distance between this and the most caudal gas collection may be of aid to the surgeon in planning his operative procedure'. The anus is at the top of the film and the axial ray appears to pass through lumbar vertebra $I$ or 2 . If this picture is to be of any service to the surgeon, the axial ray should pass through the trochantey and the anus should be near the centre of the plate. There are more pins on Fig. 87.

Fig. I0o is to illustrate a ureterocoele which is arrowed. There is no line drawing illustrating the underlying pathological entity and the illustration is unlike any ureterocoele known to the reviewer, the arrow appears to point to gas in the rectum. In Fig. IOI the child is again lying across the plate obliquely. The above films would not pass the radiographer, yet alone the radiologist of a London teaching unit engaged on daily routine work, even more so a department illustrating a monograph of radiology. In America, Caffey has written a classic on pædiatric radiology; a second book on the same subject, from the same country, should reach its standard or should exceed it.

\section{Oxytocin}

Edited by R. Caldeyro-Barcia and H. Heller. Proceedings of an International Symposium held in the University of Montevideo. Pp. xiv +443 , illustrated. Oxford, London, New York and Paris: Pergamon Press. 196I. Price $£ 5$.

This book is a record of the proceedings of an international symposium upon oxytocin that was held in the Department of Obstetric Physiology of the University of Uruguay at Montevideo during 1959.

G. W. Bissett (London), B. A. Cross (Cambridge), R. J. Fitzpatrick (Bristol), H. Heller (Bristol), Mary Pickford (Edinburgh), C. N. Smyth (London) and G. W. Theobald (Bradford) all contributed papers and were amongst the British workers who participated in the discussions.

The subject is considered under the following headings :

(I) General Physiology and Pharmacology of Oxytocin.

(2) The Mechanism of the Uterine Action of Oxytocin.

(3) Oxytocin and the Pregnant Uterus.

(4) Pharmacology of Peptides related to Oxytocin.

(5) Comparison of the Uterine Action of Oxytocin with that of other Oxytocic Substances.

(6) Oxytocinase.

(7) The Determination of Oxytocic Substances in Blood.
This is a fascinating book, the contents of which will be of more interest to the pharmacologist, the physiologist and the endocrinologist than to the practising obstetrician. It should be indispensable to all those who are interested, directly or indirectly, in the activity of the pregnant or the non-pregnant uterus. Our understanding of uterine action is far from complete and this book gives a good summary of the state of our knowledge up to the present time and it indicates the vast amount of laboratory and clinical time and research that have been devoted to this important aspect of reproduction. A large number of references are included at the end of each paper, but the absence of their exact titles detracts something from their value.

This report certainly clarifies a great deal of what is known about the action of the animal and human uterus, but such a symposium would be considered a failure if it did not define the unsolved problems and indicate the particular questions to which the clinician urgently demands an answer. Is an anti-oxytocic substance soon to be defined? What is the relationship between the actions of oxytocin and progesterone at term? What is the value of external tocographic recording? This book outlines adequately these and many other unsolved problems.

If such dedicated workers continue their investigations, then one can confidently anticipate that some of these problems will soon be solved, but the reader must remember that the results obtained from animal investigations are not always applicable to the human.

\section{Growth and Development in Childhood}

ANDREW BogdAN, M.D., M.R.C.P.E., D.C.H. Tutorial System Publications, Pædiatric Series. Pp. 2I. Publisher's agents: Austick's Medical Book Shop, Leeds. 1962. 3s. $6 d$.

This is the third booklet in the above series (the others being 'The Newly Born Infant' and 'Artificial Feeding in Early Infancy') and follows the format of the previous ones, each text page being followed by a blank page for the student's own notes. The booklets are intended solely as an aid to revision and to teaching and must not therefore be considered as textbooks.

This volume summarizes the stages of normal growth and development in an infant, the factors which influence them, and the indications of retardation. Apart from one or two misleading statements regarding toilet training, which indicate perhaps only a lack of personal practical experience on the author's part in handling small babies, this booklet should prove a useful guide for students.

\section{Great Ideas in the History of Surgery}

Leo M. Zimmerman, M.D., and Ilza Veith, Ph.D. Pp. xii +587 , illustrated. Baltimore: The Williams and Wilkins Co. London: Baillière, Tindall and Cox. 1961. 20 .

A book should be judged by its contents, not by its title. 'Vanity Fair' is an apt description of the contents of the novel with that title, but we are not disappointed when Macaulay's 'History of England' deals, in fact, with only 40 years of the I 7 th century. When, however, on the strength of a title the reader is taken for a ride particularly if it is not unpleasant, he is entitled to feel a little cheated or, if he has the temperament, irritated. For 'Great Ideas in the History of Surgery' is a misnomer for a work which is properly described as 'Lives and Writings of the Master Surgeons'. It differs from other popular works on the history of surgery by its inclusion of fairly lengthy abstracts from the writings 
of the various authors considered. These form the best part of the book and give a vivid insight into the changing as well as the unchanging aspects of surgery and surgeons. It is amusing, for instance, to read in the earlier extracts of the surgeon's preoccupation with the collection of fees and how it comes about that to this day it is a far more serious offence in medical ethics to be adulterous or drunk than professionally incompetent. Old woodcuts of unlikely-looking instruments and procedures are reproduced, and here lavishness has resulted in unnecessary duplication in some instances. The text is free of gross inaccuracies, contains small errors (University Hospital for University College Hospital and the like) and the occasional unhappy choice of expression (Wood Jones is referred to as Dr. Jones!), but the narrative nowhere flags and is written in an easy style. None of the conventions of the subject are omitted; for instance, the chapter on John Hunter is prefaced by 'I think your solution is just. But why think? Why not try the experiment?' In not heeding the message of the second sentence the authors have missed a wonderful opportunity to fill an important gap in the medical literature. The history of kings and battles is no longer considered an adequate approach to general history and it is time to cease writing comparable medical histories. In the present work humours, bleeding, acupuncture, extract of puppies, weapon salves and what have you are mentioned as matters of fact, but not discussed as ideas. John Hunter is called a genius, but no supporting evidence or reason is given for this assertion. Again, ideas good, bad and indifferent are mentioned without any comment. Though the contents of this book belie its title, nevertheless as a source of several evenings' instructive entertainment it is a complete success.

\section{Genetics of Micro-organisms}

Scientific editor: W. HAYES. British Medical Bulletin, Vol. I8, No. I, January i 962 . Pp. 88, illustrated. London: The British Council. I962. 20 .

The convenience of micro-organisms for studying biological pathways in metabolism, variation and genetics is well known and the study of these organisms has produced some of the most exciting and most basic advances in biology.

For the physician and medical research worker a knowledge of these advances and of the work leading up to them is not only of interest, but may be of importance to his own work. For this reason this symposium is invaluable. The papers include studies on the nucleic acids; genes and enzymes of micro-organisms; bacteriophage genetics and two most important papers, for the physician, on microbial genetics and chemotherapy and methods of microbial genetics in an approach to human genetics.

In a thought-provoking introduction Sir Macfarlane Burnet rightly points to the features of this field as represented by this symposium, which reveal a neglect of microbial disease and humanitarian medicine in general, but ends with a hope: that the study of mammalian somatic cell genetics will be of help in the elucidation of degenerative and malignant disease in the process of ageing.

Perhaps the most disturbing feature is the work on the genetics of virulence in bacteria. Sir Macfarlane questions its use except in bacteriological warfare. Though a case could be put for this type of research, it is significant that the author, Dr. T. W. Burrows, begi his paper with a near-apology both for the work he doing and the place where it is done.

This is probably one of the best concise sources modern developments in the fields of structure and chemical behaviour of DNA and RNA, the genet control of enzyme synthesis and cellular metabolisnn, the morphology of the bacterial nucleus and its possib. importance in chromosome studies, bacterial replicatio the bacteriophages, to mention only a few of the subject

\section{The Senile Brain: A Clinical Study}

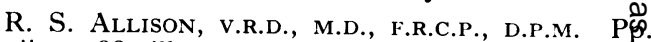
vii +288 , illustrated. London: Edward Arnolக્ळ I962. 50s.

It is the subtitle of this book which tells us what it $\overrightarrow{\dot{d}}$ really about, for there is nothing about the histology \& pathology of the brain in old people within its cove as might be expected from the title. But those who reat it will be well rewarded, for it is an excellent clinical account of the organic failure of mental function whiẹ afflicts some people in later life. The book is obvious written by one with a wealth of clinical experienco behind him; the excerpts from conversations with patients could only have come from a deeply interestef observer who had been dealing with patients with dementia for a long time past.

The earliest chapters which describe how to set about the task of examining a patient with a possible dementia will be found most valuable. So often in this situatid the student or the doctor unaccustomed to dealing wi these problems is at a loss how to proceed. He find wise guidance here. The importance of catses outside the nervous system as responsible for dement is well stressed by an abundance of apt illustrations and how important it is for neurologists and psychiatrist to remain always general physicians is made appafint? This book is to be highly commended and will bec valuable guide to doctors faced with the problem of the dementing patient.

\section{Surgery of the Stomach and Duodenum}

Edited by H. M. HaRKINS, M.D., PH.D., F.A.C.s. and L. M. Nyhus, M.D., F.A.C.s. Pp. xvi +736 , wit 230 figures. London: J. and A. Churchill. 1968 Eio.

This is a magnificent work; 43 authors-not on from the U.S.A. but also including Koster of Copen hagen and our own Norman Tanner and Hermळ Taylor-present an authoritative review of the anatom physiology, pharmacology, diagnostic techniques and surgery of the stomach and duodenum. Caref editorial work has prevented the book from becoming series of disjointed articles, indeed throughout the woe surgical approach is based on a sound background of physiology and experimental investigation. Moreover most chapters end with editorial comments and or special comments from other authorities, so that conflicti views on controversial subjects can be succinct presented.

The book is beautifully produced and illustrate $\stackrel{N}{?}$ the references are exhaustive, international and up-toj date. Although packed with information it is of a sise and shape that makes reading a pleasure. Its price ma prove a serious handicap to many readers but its eq cylopædic nature will make it a valuable addition to aæ hospital library.

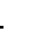

